Elsevier required licence: (c) 2017. This manuscript version is made available under the CC-BY-NC-ND 4.0 license http://creativecommons.org/licenses/by-nc-nd/4.0/ 


\section{Evaluation the Potential and Energy Efficiency of Dual Stage Pressure Retarded Osmosis Process}

Ali Altaee ${ }^{1}$, Guillermo Zaragoza ${ }^{2}$, Enrico Drioli ${ }^{3}$, John Zou ${ }^{1}$

${ }^{1}$ School of Civil and Environmental Engineering, University of Technology Sydney, 13 Broadway, Ultimo, NSW 2007, Australia. Email: ali.altaee@uts.edu.au; Tel: +61420606500. ${ }^{2}$ CIEMAT, Plataforma Solar de Almería, Ctra. de Senés s/n, 04200

Tabernas, Almería, Spain. ${ }^{3}$ Institute on Membrane Technology (ITM-CNR), National Research Council, c/o University of Calabria, Cubo 17C, Via Pietro Bucci, 87036 Rende CS, Italy.

\section{Abstract:}

Power generation by means of Pressure Retarded Osmosis (PRO) has been proposed for harvesting the energy of a salinity gradient. Energy recovery by the PRO process decreases along the membrane module due to depleting of the chemical potential across the membrane and concentration polarization effects. A dual stage PRO (DSPRO) design can be used to rejuvenate the chemical potential difference and reduce the concentration polarization on feed solution. Several design configurations were suggested for the membrane module arrangements in the first and second stage of the PRO process. PRO performance was evaluated for a number of salinity gradients proposed by coupling Dead Sea water or Reverse Osmosis (RO) brine with seawater or wastewater effluent. Maximum specific energy of inlet and outlet feeds was calculated using a developed computer model to identify the amount of recovered and remaining energy. Initially, specific power generation by the PRO process increased by increasing the number of modules of the first stage. Maximum specific energy is calculated along the PRO module to understand the degradation of the maximum specific energy in each module before introducing a second stage PRO process. Adding a second stage PRO process resulted in a sharp increase of the chemical potential difference and the specific energy yield of the process. Between $10 \%$ and $13 \%$ increase of the specific power generation was achieved by the DSPRO process for the Dead Sea-seawater salinity gradient depending on the dual stage design configuration. For Dead Sea-RO brine, 12\% to $16 \%$ increase of the specific power generation was achieved by the dual stage PRO process. For Dead Sea-wastewater and RO brine-wastewater, a neutral and sometimes negative impact occurred when a second stage PRO process was introduced. We concluded that, for a given draw solution concentration, dual stage performs better than the conventional PRO process at high feed salinities, yet requires lower hydraulic pressure.

Keywords: Dual Stage Pressure Retarded Osmosis, Osmotic Energy, Osmotic Power Plant, Pressure Retarded Osmosis, Salinity Gradient Resource 


\section{Introduction:}

Salinity gradient is an interesting resource for power generation which is increasingly acknowledged as a cheap and efficient way for renewable energy [1-2]. Currently, there are two main techniques to extract energy from a salinity gradient; Reverse Electrodialysis (RED) and Pressure Retarded Osmosis (PRO). The former uses a stack of anion and cation exchange membranes placed in alternate positions to generate a voltage difference from the chemical potential difference of two solutions [3]. The latter has been under investigation over the last four decades [4-7]. PRO process converts the chemical potential of a salinity gradient resource into a hydrostatic potential and eventually to an energy source after passing through a hydro turbine system [6]. At onset, technical issues represented by finding a suitable membrane have adversely affected the efficiency of PRO process and lessened its attractiveness for further development [8-9]. Low membrane flux has been attributed to the severe concentration polarization (CP) phenomenon at the solution-membrane interface [9]. Intensive research, however, has led into the development of better performance PRO membranes and revolutionized the process [10-13]. Unsurprisingly, the number of research studies to explore the potential of PRO process on osmotic power plants has been increased over the last decade [14-18].

Developing a PRO membrane was a step forward towards high performance PRO process but has not entirely resolved the issue of unsatisfactory performance due to the concentration polarization effects and low chemical potential difference of a salinity gradient resource. Statkraft PRO pilot plant, the world first osmotic power plant, was a setback for the PRO process; the plant shut down shortly after starting due to an unsatisfactory performance [20]. Nevertheless, recent pilot plant studies reported 13.3 $\mathrm{W} / \mathrm{m}^{2}$ power density using a modified four ports Toyobo hollow fiber (HF) membrane and RO brine-wastewater effluent as a salinity gradient resource [10]. The modified Toyobo membrane has been able to reduce the effect of concentration polarization and maintaining the satisfactory power density at 30 bar hydraulic pressure. Pairing RO brine with wastewater effluent has overcome the problem of insufficient membrane flux associated with the low chemical potential of a salinity gradient resource which has been encountered in the Statkraft pilot plant. Mega-ton project has demonstrated a recurring interest in the process and potential application for power generation [21]. The other interesting finding which has been demonstrated by the project was the membrane capability to withstand an operating pressure of 30 bar [10]. This reflects the high mechanical strength of the new developed Toyobo membranes which has been an obstacle in the past. The application of high concentration brine (such as Dead Sea water) has been suggested in a number of studies to boost the performance of PRO process $[8,2017,22]$. However, the effects of concentration polarization and reverse salt diffusion on the membrane flux and performance intensify at elevated draw solution concentrations; this has been experimentally demonstrated in several studies 
$[23,24]$. Ignoring the effects of concentration polarization, a maximum power density of $230 \mathrm{~W} / \mathrm{m}^{2}$ can be achieved when Dead Sea water is coupled with $35 \mathrm{~g} / \mathrm{L}$ seawater [25]. The maximum power density drops down to $70 \mathrm{~W} / \mathrm{m}^{2}$ when the effect of concentration polarization is taken into account [25]. The implication of concentration polarization phenomenon on the performance of PRO process is usually realized by the reduction of membrane flux and power density. This affects the maximum osmotic energy that can be harvested by the PRO process especially when the concentration polarization phenomenon acts on both sides of the membrane. Unfortunately, concentration polarization is an inevitable phenomenon in the osmotically driven membrane technologies and can not be eliminated even in the most developed PRO membranes.

In non-ideal systems, PRO process can only recover part of the salinity gradient energy while the non-recoverable energy remains in the salinity gradient resource for discharge. Practically, this reduces the efficiency of PRO process and makes its application less productive. Recent research has suggested adding a second stage PRO process to capture the rest of osmotic energy from the diluted draw solution before discharge [2527], hence maximizing the energy efficiency of PRO process. The diluted draw solution from the first stage and a raw feed solution are coupled to form the salinity gradient of the second stage [Figure 1]; this will rebuild the chemical potential difference across the PRO membrane. Therefore, the thermodynamic limits of conventional (single stage) and dual stage PRO process are different. Practically, the rejuvenated salinity gradient resource of the second stage of the dual stage PRO (DSPRO) induces a tangible increase of water flux across the PRO membrane. Previous studies referred to the advantage of DSPRO in reducing PRO membrane fouling when two different sources of feed solution were coupled with a draw solution [26]. The effect of feed and draw solution flow rates, feed pressure, and feed concentration on the performance of conventional PRO was evaluated in the previous studies [15]. However, the performance of DSPRO process needs to be characterized in terms of thermodynamic limits of the process and specific energy yield along the PRO module. This will provide more knowledge about the preferable configuration of membranes arrangement for the DSPRO process and justification for use instead of the conventional PRO process.

In this paper, we performed an energy comparison simulation study between the conventional PRO and the DSPRO process to evaluate the energy efficiency of each system. Typically, the chemical potential of salinity gradient resources decreases along the membrane [17-18]. To address the impact of increasing number of membrane modules or area on the performance of PRO process, we suggested a number of scenarios for membrane modules arrangement and configuration in the first and second stage of the PRO process. Each design configuration addressed the impact of salinity gradient concentration and feed hydraulic pressure on the performance of single and DSPRO processes. The simulation results were analyzed to explain the advantages of the DSPRO compared with the conventional PRO process. 


\section{A: DSPRO}

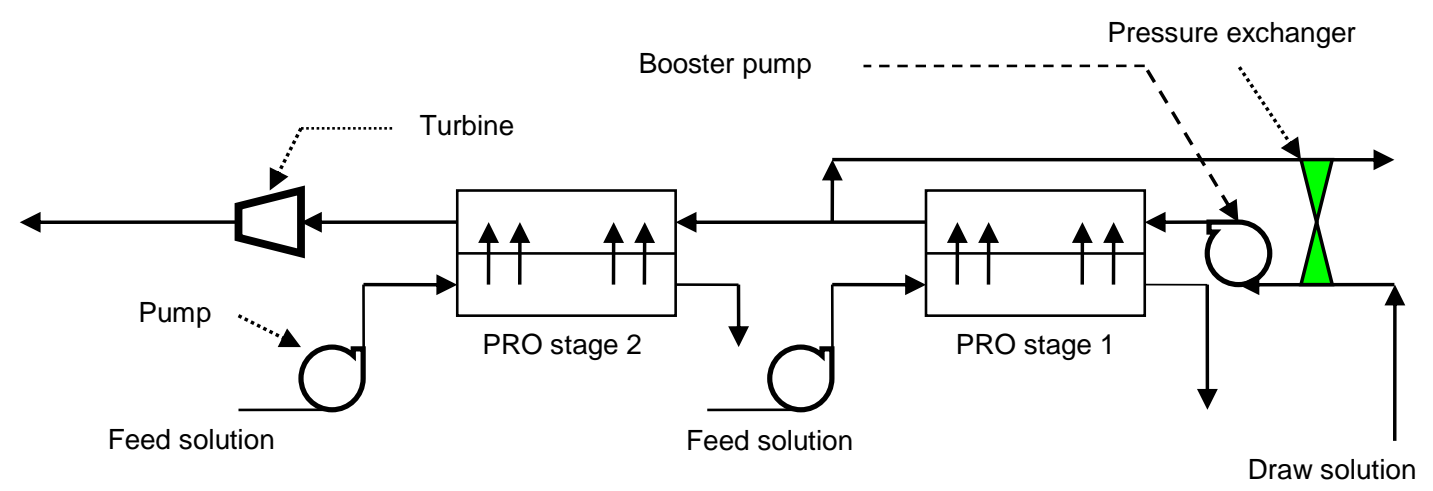

\section{B: PRO Membrane}

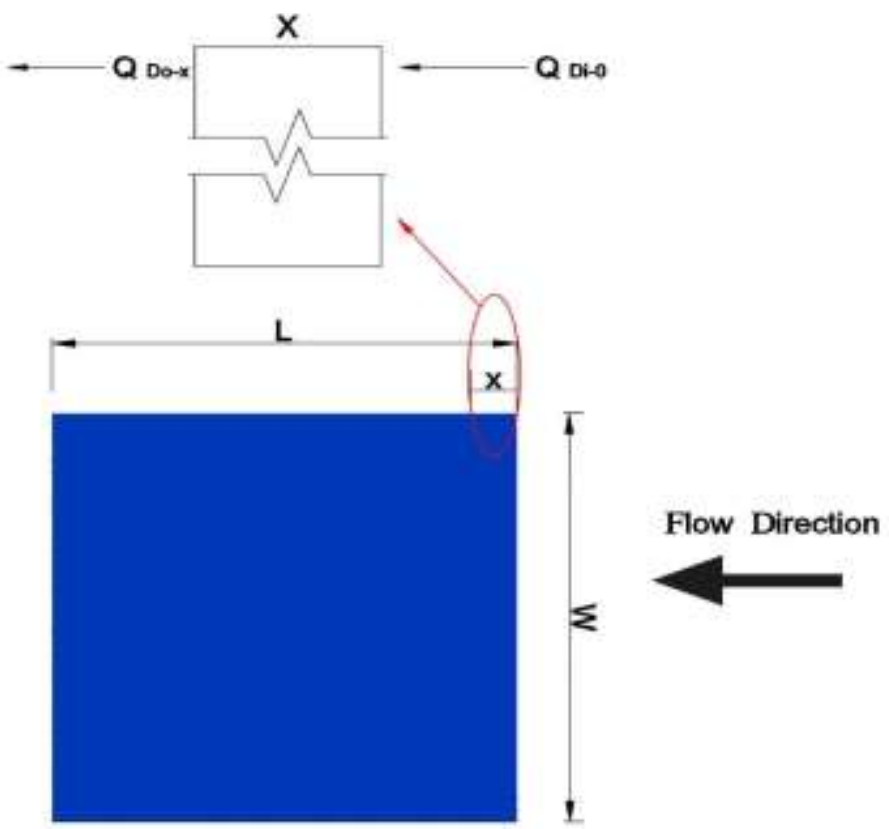

Figure 1: A) Schematic diagram of Dual Stage PRO process; B) Cross section of PRO membrane.

\section{Effect of membrane area:}

The driving force across the membrane in the PRO process is the osmotic pressure of the salinity gradient resource. Accordingly, the higher the difference between the concentration of draw and feed solutions is, the larger the driving force across the PRO membrane. As fresh water permeates across the membrane, draw solution becomes more diluted whereas the feed solution gets concentrated. This suggests that the driving force across the membrane decreases along the membrane module and adversely affects the permeate flow of the PRO process. Thermodynamically, the maximum energy that can be generated by the PRO process equals to the Gibbs free energy of mixing. However, the maximum specific energy that can be harvested by the PRO 
process is only $70 \%$ to $90 \%$ of the specific Gibbs free energy of mixing for countercurrent PRO process [17]. Interestingly, the upper bound of the maximum extractable specific energy was in the case of Dead Sea-RO brine salinity gradient resource compared to the other salinity gradient resources in which the feed solution was a river water or wastewater. The expression used to calculate the maximum specific energy, $E_{\max }$, was derived from the equation of Gibbs free energy of mixing, $\Delta G_{n M}$ [17]. Theoretically, $E_{\text {max }}$ yield of a PRO process operating in a countercurrent mode and under constant pressure can be calculated from the following equation [17]:

$E_{\max }=\frac{n R T\left(C_{D}-C_{F}\right)^{2}}{4\left(C_{D}-C_{F}\right)}$

where, $n$ is number of ions in solution, $R$ is the gas constant, $T$ is the temperature in Kelvin, $C_{D}$ is the initial molar concentration of draw solution, and $C_{F}$ is the initial molar concentration of feed solution. In the case of using multi membrane modules, feed and draw solutions at the outlet of first PRO module form the salinity gradient resource for the second PRO module. The specific energy of the inlet and outlet salinity gradient resource, $E_{i}$ and $E_{o}$ respectively, can be calculated from the relevant inlet and outlet concentrations of draw and feed solutions. For two membrane modules PRO process, the specific energy of the outlet salinity gradient resource from the second membrane module represents the specific energy of the salinity gradient resource which has not been recovered by the PRO process, and is usually dissipated when the salinity gradient is discharged. The specific energy of outlet salinity gradient, which exits the PRO module, normalized by the maximum specific energy of salinity gradient resource gives the normalized specific energy ratio, $S$, as in the following equation:

$S=\frac{E_{o}}{E_{\max }}$

where, $E_{\mathrm{o}}$ is the specific energy of the outlet salinity gradient resource, and $E_{\max }$ is the maximum specific energy of the salinity gradient resource. $S$ ratio represents the specific energy of the salinity gradient which has not been recovered by the PRO process; i.e. high $S$ ratio refers to low energy recovery by the PRO process. Practically, PRO process is unable to recover the entire osmotic energy of a salinity gradient resource due to the process limitations represented by the concentration polarization and reverse salt diffusion. For non-ideal system, therefore, energy recovery by the PRO process would be lower than the maximum specific energy. The unrecovered osmotic energy by the PRO process is the specific energy of salinity gradient resource exiting the membrane; this energy is referred to $E_{o}$ in Equation 2.

For non-ideal system, energy recovery by the PRO process is lower than the maximum recoverable specific energy due to the effects of concentration polarization and salt back diffusion. DSPRO design concept manipulates the chemical potential difference 
across the membrane to reduce the effect of concentration polarization and minimize $E_{o}$ at the end of the process hence improving the process efficiency. Therefore, the effects of concentrative and dilutive concentration polarization were considered in estimating membrane flux of the PRO process.

Previous studies suggested the following expression to calculate the membrane flux, $J_{w}$, of the PRO process [14]:

$$
J_{w}=A_{w}\left(\frac{\pi_{D b} e^{\left(\frac{\left.-J_{w}\right)}{k}\right.}-\pi_{F b} e^{\left(J_{w} K\right)}}{1+\frac{B}{J_{w}}\left(e^{\left(J_{w} K\right)}-e^{\left(\frac{-J_{w}}{k}\right)}\right)}-\Delta P\right)
$$

where, $\pi_{D b}$ and $\pi_{F b}$ are the osmotic pressures of the bulk draw and feed solution, respectively, $A_{w}$ is the water permeability coefficient, $\Delta P$ is the hydraulic pressure across the PRO membrane, $k$ is the mass transfer coefficient, $B$ is the solute permeability coefficient, $K$ is the solute resistivity for diffusion within the porous support layer, and $A$ is the membrane area. Equation 3 was experimentally developed to calculate $J_{w}$ in a bench scale flat sheet membrane coupon. Yet, there is not any empirical formula to accurately calculate $J_{w}$ in a full scale membrane module; hence equation 3 has been suggested for rough estimation of the membrane flux in a full scale membrane module [18]. Based on the previous study [18], the key parameters in Equation 3 were assumed as the following $A_{w}=6.7^{*} 10^{-4} \mathrm{~m} / \mathrm{h} \cdot$ bar, $B=4 * 10^{-4} \mathrm{~m} / \mathrm{h}, k=0.306 \mathrm{~h} / \mathrm{m}$, and $K=23 \mathrm{~h} / \mathrm{m}$. The temperature of feed and draw solution was $20{ }^{\circ} \mathrm{C}$ when the osmotic pressure was calculated. Equal feed and draw solution flow rates were assumed in the first and second stage and the initial flow rate of the first stage was $2000 \mathrm{~L} / \mathrm{m}^{3}$. The bulk concentration of draw solution, $C_{D B}$, is the average of inlet and outlet concentration of draw solution. We assumed PRO module of $L$ length and divided into $j$ number of equal sections; the length of each section is $x$ (Figure 1B). The bulk concentration of draw solution at distance $x$ from the membrane inlet, $C_{D b-x}$, was estimated from the following equation:

$C_{D b-x j}=\frac{C_{D i-x j}+C_{D o-x j}}{2}$

where, $C_{D i-x j}$ and $C_{D o-x j}$ are the inlet and outlet concentrations of draw solution at distance $x$, and $j$ is the number of section along the PRO module. We assumed a linear distribution of the bulk concentration due to insignificant difference compared to the logarithmic concentration of bulk solution $[17,18,29]$. Assuming a PRO membrane of perfect rejection to solutes, i.e. reflection coefficient is equal to a unity; the concentration of outlet draw solution is calculated from mass and flow balance equation. At the entrance of the first PRO module, the inlet concentration of draw solution; i.e. 
$C_{D i-x j}=C_{D i-x 1}$, is already known whereas the outlet concentration of draw solution, $C_{D o-x j}=$ $C_{D o-x 1}$ is obtained from mass and flow balance of draw solution [15]:

$C_{D o-x j}=\frac{C_{D i-x j} Q_{D i-x j}}{Q_{D o-x j}}$

where, $Q_{D i-x j}$ is the draw solution inlet flow rate, $C_{D i-x j}$ is the draw solution inlet concentration and $Q_{D o-x j}$ is the draw solution outlet flow rate. The calculated output parameters from the previous section will be the input parameter of next section; i.e. $Q_{D o-x 1}=Q_{D i-x 2}$ and $C_{D o-x 1}=C_{D i-x 2}$. Furthermore, $Q_{D o-x j}$ is the sum of inlet flow rate of draw solution, $Q_{D i-x j}$, and permeate flow rate, $Q_{p-x j}$, as in the following expression:

$Q_{D o-x j}=Q_{D i-x j} Q_{p-x j}$

Compensating equation 5 in Equation 4 to give:

$C_{D b-x j}=\frac{C_{D i-x j}\left(1+\frac{Q_{D i-x j}}{Q_{D o-x j}}\right)}{2}$

Similarly, the bulk concentration of feed solution, $C_{F b-x j}$, is calculated from averaging the inlet and outlet concentrations of feed solution as in Equation 8:

$C_{F b-x j}=\frac{C_{F i-x j}+C_{F o-x j}}{2}$

where, $C_{F i-x j}$ and $C_{F o-x j}$ are the concentration of inlet and outlet feed solution. The concentration of outlet solution is calculated form the mass and flow balance at the draw solution side of the PRO membrane as the following [15]:

$C_{F o-x j}=\frac{C_{F i-x j} Q_{F i-x j}}{Q_{F o-x j}}$

where, $C_{F i-x j}$ is the feed solution inlet concentration, $Q_{F i-x j}$ is the feed solution inlet flow rate and $Q_{F o-x}$ is the feed solution outlet flow rate. And $Q_{F o-x j}$ is equal to the difference between $Q_{F i-x}$ and $Q_{p-x}$; i.e. $Q_{F o-x j}=Q_{F i-x j}-Q_{p-x j}$. Compensating equation 9 in equation 8 gives: 
$C_{F b-x j}=\frac{C_{F i-x j}\left(1+\frac{Q_{F i-x j}}{Q_{F o-x j}}\right)}{2}$

Equations 7 and 10 estimate the bulk concentration of draw and feed solutions respectively; substituting equations 7 and 10 in equation 3 and using Van't Hoff equation for the osmotic pressure calculation:

$$
J_{w-x j}=A_{w}\left(\frac{\left(n R T C_{D i-x j}\left(1+\frac{Q_{D i-x j}}{Q_{D o-x j}}\right) / 2\right) e^{\frac{-J_{w-x j}}{k}}-\left(n R T C_{F i-x j}\left(1-\frac{Q_{F i-x j}}{Q_{F o-x j}}\right) / 2\right) e^{J_{w-x j} K}}{1+\frac{B}{J_{w-x j}}\left(e^{J_{w-x j} K}-e^{\frac{-J_{w-x j}}{k}}\right)}-\Delta P\right)
$$

where, $\eta$ is number of ions in the solute, $R$ is the gas constant, and $T$ is the Kelvin temperature $\left(25^{\circ} \mathrm{C}+298\right)$. It should be noted that feed concentrations in Equation 11 are in molar concentration. $J_{w-x j}$ represents the membrane volumetric flow rate at distance $x$. The outlet concentration of draw and feed solutions, $C_{D o-x j}$ and $C_{F o-x j}$, respectively, are calculated from rearranging equations 4 and 8 as the following:

$$
\begin{aligned}
& C_{D o-x j}=2 C_{D b-x j}-C_{D i-x j} \\
& C_{F o-x j j}=2 C_{F b-x j}-C_{F i-x j}
\end{aligned}
$$

where, $C_{D b-x j}$ and $C_{F b-x j}$ are the bulk concentration of draw and feed solutions. The local maximum specific energy of salinity gradient resource, $E_{o-x j}$, is defined as the maximum specific energy of the salinity gradient resource at distance $x j$ along the membrane module and can be calculated from the respective draw and feed concentrations as in the following equation:

$$
E_{o-x j}=\frac{n R T\left(C_{D o-x j}-C_{F o-x j}\right)^{2}}{4\left(C_{D o-x j}-C_{F o-x j}\right)}
$$

The local maximum specific energy is normalized by the maximum specific energy of the salinity gradient resource as in the following equation:

$$
S_{x j-N}=\frac{E_{o-x j}}{E_{\max }}
$$


where, $S_{x j-N}$ is the normalized local maximum specific energy ratio. The normalized power generation by the PRO process is function of the hydraulic pressure, permeate flow, and feed flow rate:

$$
E s_{-x j}=\frac{\Delta P Q_{p-x j}}{Q_{F T-x j}}
$$

where, $E s_{-x j}$ is the specific power generation by the PRO process, $\Delta P$ is the hydraulic pressure of the draw solution, $Q_{p-x j}$ is the permeate flow rate, and $Q_{F T-x j}$ is the total flow rate of feed and draw solutions. In non-ideal system, the harvested specific energy by the PRO process is lower than the theoretical maximum specific energy estimated by equation 1 due to the reverse salt diffusion and effects of concentration polarization. However, the energy yield of PRO process can be maximized by adding extra modules to increase the membrane area [18]. The impact of membrane area on the energy efficiency of PRO process can be evaluated by calculating the local maximum specific energy along the membrane module. At any point along the PRO module, $S_{x j-N}$ value represents the fraction of the osmotic energy ratio of the salinity gradient resource which is unrecovred by the PRO process. Typically, $S_{x j-N}$ decreases along the membrane module due to the dilution and concentration of the draw and feed solutions respectively.

The effect of adding an extra PRO module was evaluated assuming the length of PRO module is $1 \mathrm{~m}$ whereas the length of each $x$ section is $0.1 \mathrm{~m}$ and there are two PRO modules in series inside the PRO pressure vessel. Figure 2A shows a gradual decrease of the $S_{x j-N}$ along the membrane modules due to the dilution and concentration of draw and feed solution, respectively. This results in a reduction of the chemical potential difference of the salinity gradient resource. Adding a second PRO module caused a further reduction of $S_{x j-N}$ due to increased energy recovery of the PRO process. The impact of salinity gradient resource type on the specific energy recovery by the PRO process is illustrated in Figure 2A. $S_{x j-N}$ of the salinity gradient resource at the outlet of first PRO module (1 meter long) represents the osmotic energy which has not been captured by the process; the $S_{x j-N}$ at the outlet of first PRO module was $55 \%, 58 \%$ and $68 \%$ for Dead Sea-RO brine, Dead Sea-seawater and Dead Sea-wastewater salinity gradients respectively. The corresponding values for RO brine-wastewater and seawater-wastewater salinity gradients were $82 \%$ and $88 \%$ respectively; this refers to the low energy recovery by the first membrane module. In general, elevated $S_{x j-N}$ values are an indicative of the low energy yield of the PRO process. Figure $2 \mathrm{~A}$ also shows that $S_{x j-N}$ at the outlet of second PRO module was higher in the case of Dead Sea-wastewater compared to the Dead Sea-seawater and Dead Sea-RO brine salinity gradient resources. This was attributed to the higher chemical potential difference across the membrane in the case of Dead Sea-wastewater salinity gradient resource. In this case, more membrane area is probably required for harvesting the energy of the salinity gradient resource. One of the limitations for increasing the number of membrane modules is the 
inadequate membrane flux which decreases with the number of PRO modules [Figure $2 B]$. For example, membrane flux decreased by factor of five, from $23 \mathrm{~L} / \mathrm{m}^{2} \mathrm{~h}$ to $5 \mathrm{~L} / \mathrm{m}^{2} \mathrm{~h}$, at the end of PRO process for Dead Sea-RO brine.

We also calculated the power generation by each PRO module at an optimum hydraulic pressure of $\Delta P=\frac{\Delta \pi}{2}$ to confirm the energy-efficiency of each membrane module in the PRO process. Power generation by the first membrane module was $55 \%$ to $68 \%$ of the total power generated by the PRO process [Figure 3]. For Dead Sea-seawater, power generation by the first PRO module was $68 \%$ of the total power generation. Adding a second membrane module increased the power generation of the PRO process but there is a limitation on adding extra modules due to the sharp decrease of the membrane flux [Figure 2B]. The combined effect of internal and external concentration polarization reduces chemical potential difference across the membrane which is usually manifested in a sharp drop of membrane flux across. This is particularly important at high concentration feed solutions which promotes the effect of concentrative concentration polarization. For example, Dead Sea-seawater salinity gradient resulted in a reduction of membrane flux from $33 \mathrm{~L} / \mathrm{m}^{2} \mathrm{~h}$ at the beginning of the first PRO module to $6.6 \mathrm{~L} / \mathrm{m}^{2} \mathrm{~h}$ at the end of the second PRO module; this is about 5 times lower than initial membrane flux [Figure 2B]. For seawater-wastewater and RO brine-wastewater, membrane flux decreased from $19 \mathrm{~L} / \mathrm{m}^{2} \mathrm{~h}$ to $10 \mathrm{~L} / \mathrm{m}^{2} \mathrm{~h}$ at the end of second PRO module. Therefore, increasing the number of membrane modules will not significantly improve the performance of PRO process.

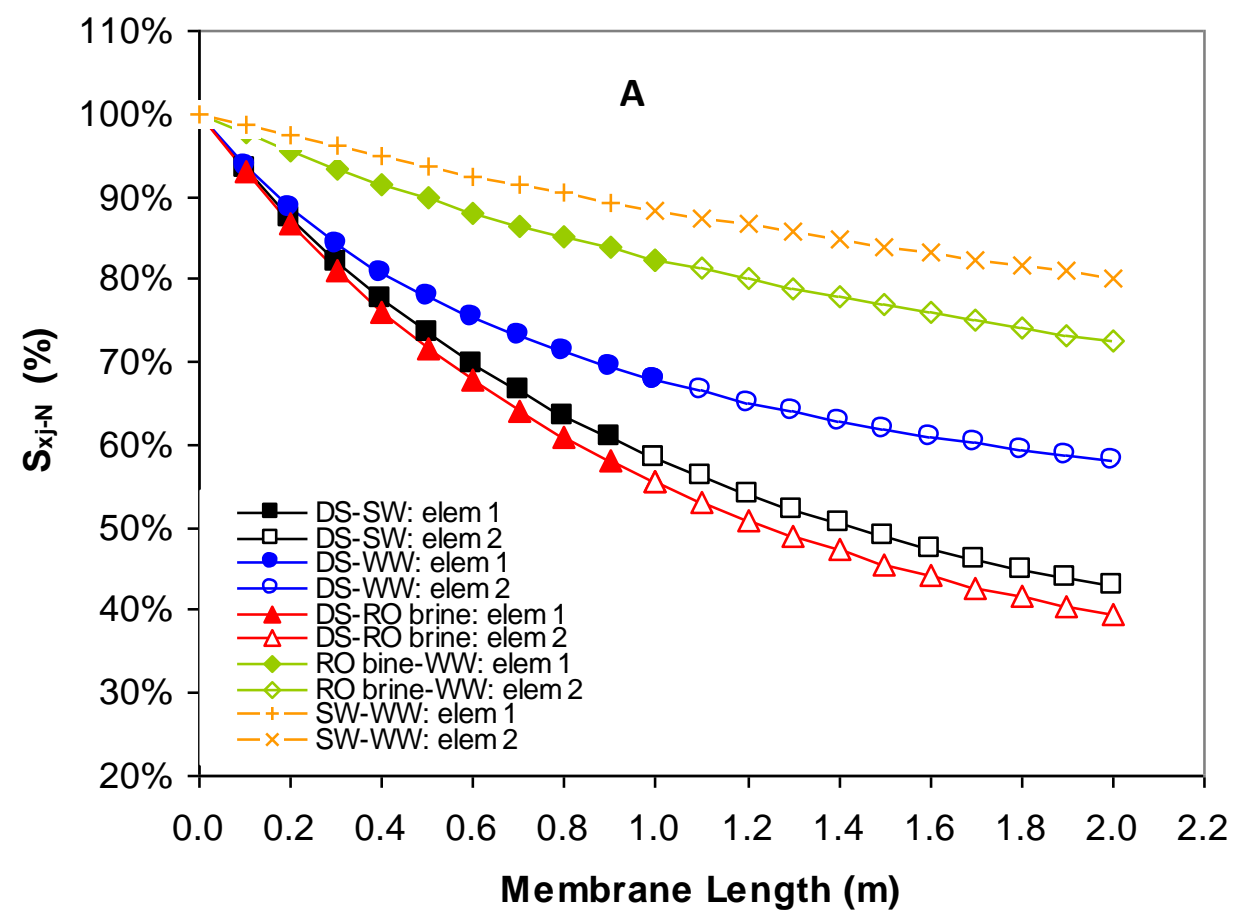




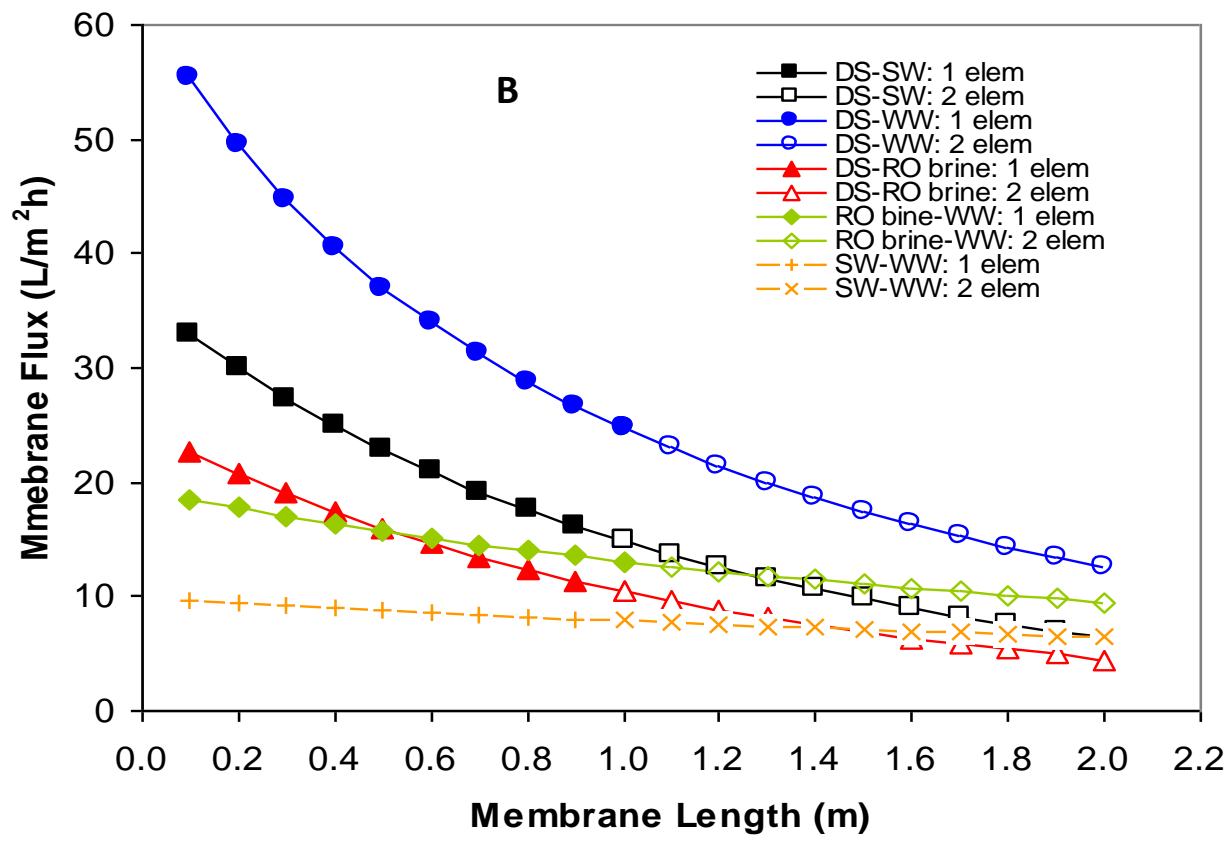

Figure 2: Energy potential and membrane flux along PRO modules in the pressure vessel: A) maximum specific energy ratio of outlet salinity gradient; B) membrane flux along the membrane module. Dead Sea water (DS) is $5 \mathrm{M} \mathrm{NaCl}$; RO brine is $1.2 \mathrm{M} \mathrm{NaCl}$; seawater (SW) is $0.6 \mathrm{M} \mathrm{NaCl}$; and wastewater (WW) is $0.017 \mathrm{M} \mathrm{NaCl}$. The length of PRO module is $1.0 \mathrm{~m}$ and there are 2 modules in the pressure vessel, each $x$ section is $0.1 \mathrm{~m}$ length and $1 \mathrm{~m}$ width, feed and draw solution flow rates are equal to $2000 \mathrm{~L} / \mathrm{h}, \mathrm{PRO}$ module area is $24 \mathrm{~m}^{2}$ 


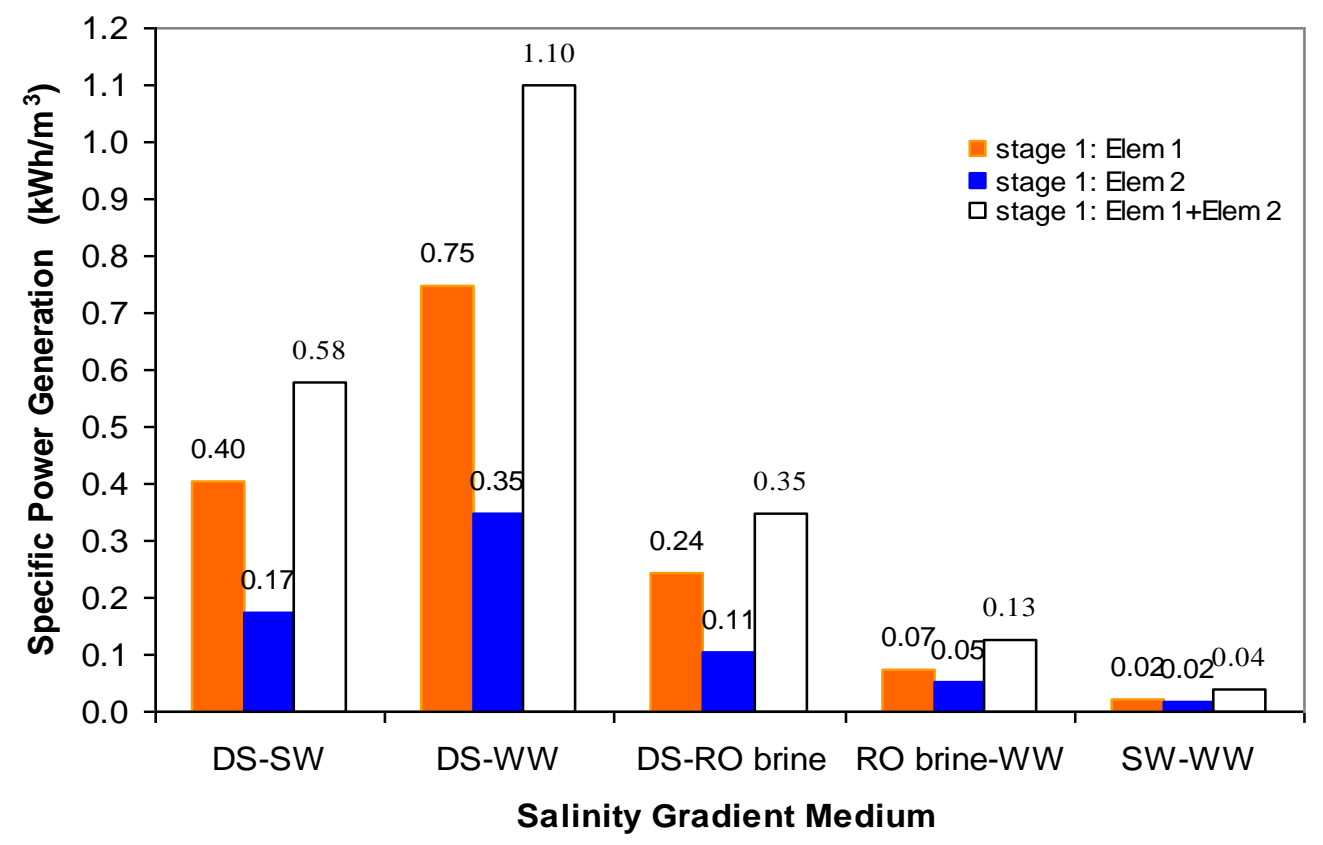

Figure 3: Specific power generation of element 1, and element 2 at different salinity gradient resources. Dead Sea water (DS) is $5 \mathrm{M} \mathrm{NaCl}$; RO brine is $1.2 \mathrm{M} \mathrm{NaCl}$; seawater $(\mathrm{SW})$ is $0.6 \mathrm{M} \mathrm{NaCl}$; and wastewater $(\mathrm{WW})$ is $0.017 \mathrm{M} \mathrm{NaCl}$. The length of PRO module is $1.0 \mathrm{~m}$ and there are 2 modules in the pressure vessel.

\section{Increase number of stages}

Several techniques have been used to enhance the performance of PRO process such as increasing the concentration of draw solution to promote water flux across the membrane $[17,25]$. However, the performance of PRO process can not always be improved by increasing the chemical potential difference across the PRO membrane due to the phenomenon of concentration polarization. Although high water flux across the membrane is desirable in the PRO process, it intensifies the effect of concentrative and dilutive concentration polarization at the feed and draw solution sides respectively. The combined effects of concentrative and dilutive concentration polarization reduce the membrane flux along the PRO module and the potential energy recovery from a salinity gradient resource. Unfortunately, the phenomenon of concentration polarization is inevitable in the osmotically driven membrane filtration processes and can not be avoided [28].

Osmotic energy is the main driving force in the PRO process; that is the difference in the osmotic pressure between the draw and feed solutions. Water permeation is induced by the osmotic pressure gradient across the membrane; hence the osmotic energy of salinity gradient resource decreases along the membrane module as the draw solution gets more diluted. On the other side of the membrane, feed solution becomes more concentrated which results in a sharp drop of the chemical potential difference across 
the membrane. Concentrative concentration polarization, in particular, can not be easily alleviated and it increases with the increase of permeation flow. Recent studies proposed DSPRO process to enhance energy recovery from a salinity gradient resource [Figure 1] [25]. The first stage of the DSPRO is similar to a conventional (single stage) PRO process with the difference that part of the diluted draw solution, equals to the permeate flow rate, goes to a second stage PRO membrane instead of to a hydro turbine. A raw feed solution is used in the second stage of the DSPRO process [Figure 1]. Replacing the concentrated feed solution with a raw feed solution will restore the salinity gradient resource across the membrane and allow extra energy to be recovered by the PRO process. The second stage of the DSPRO process requires lower membrane area than the first stage because of the low feed flow rates into the PRO module. The membrane area of the second stage is estimated as the ratio of the first stage to second stage flow rates multiplied by the first stage membrane area. The second stage

membrane area is normalized by the membrane area of the first stage as in the following expression:

$A_{2-n o r m}=\frac{Q_{F 2}}{Q_{F 1}}$

where, $A_{2 \text {-norm }}$ is the normalized membrane area of the second stage of the DSPRO process, and $Q_{F 1}$ and $Q_{F 2}$ are the first and second stage feed solution flow rate. Practically, the draw solution flow rate of the second stage is equal to the permeate flow rate of the first stage hence second stage would require lower membrane area than the first stage. We assumed a negligible pressure loss in the first stage of the DSPRO process, hence feed pressure in the second stage is equal to that of the first stage of the DSPRO. Equation 11 was applied to calculate the membrane flux of the second stage using the respective feed concentrations. Several scenarios were suggested for the membrane modules arrangement in the first and second stage of the DSPRO process as illustrated in Table 1. These scenarios were suggested to evaluate the performance of single and dual stage PRO processes having equal number of PRO module and to provide an insight about the energy efficiency of each system based on the PRO modules configuration. This would also suggest the best configuration of PRO module arrangement in the pressure vessel to maximize the energy yield of the PRO process from a salinity gradient resource. A maximum number of three PRO modules were evaluated for the PRO process; this is because of the sharp drop of membrane flux with increasing the number of membrane modules as will be discussed later. Scenario one is the baseline for a conventional PRO process of a single membrane module. The number of PRO modules increased to two in scenario two for comparison with scenario four which has one element in each stage of the DSPRO process. Three PRO modules were considered in the conventional PRO in scenario 3 and used for comparison with scenarios five and six which represent the DSPRO process. Scenario five suggested one and two modules in the first stage and second stage of the DSPRO process respectively. 
And finally, scenario six suggested two and one module in the first stage and second stage of the DSPRO process respectively.

Table 1: PRO membrane modules arrangements in the first and second stage of the DSPRO process, the first two options are default for the conventional PRO process. Options 3 to 5 are for the DSPRO process; maximum number of modules was assumed three in the DSPRO process

\begin{tabular}{|c|c|c|}
\hline Scenario & Modules arrangement configurations & Symbol \\
\hline 1 & One module in the first stage only & $1-0$ \\
\hline 2 & Two modules in the first stage only & $2-0$ \\
\hline 3 & Three modules in the first stage only & $3-0$ \\
\hline 4 & One module in the first stage and second stage & $1-1$ \\
\hline 5 & One module in the first stage and two modules in the second stage & $1-2$ \\
\hline 6 & Two modules in the first stage and one module in the second stage & $2-1$ \\
\hline
\end{tabular}

Scenarios 1 to 3 in Table 1 illustrate the impact of increasing the number of PRO modules on the conventional PRO process performance which was early explained. Figure 4A shows PRO processes in which Dead Sea (DS) water was the draw solution whereas in Figure 4B RO brine and Seawater (SW) were the draw solutions. Increasing the PRO modules from one to three of the conventional PRO process resulted in up to $70 \%$ increase of the power generation when Dead Sea water was coupled with wastewater as the feed solution [Figure 4A]. Using three PRO modules instead of one in the conventional PRO increased the power generation by 1.5 times for the seawaterwastewater salinity gradient resource [Figure 4B]. A comparison between scenario 2 and scenario 4 would explain the dependence of the DSPRO performance on the type of salinity gradient resource. In the case of Dead Sea-wastewater, RO brine-wastewater, and seawater-wastewater, a neutral or negative impact on the osmotic energy yield occurred when scenario 4 of the DSPRO replaced scenario 2 of the conventional PRO. For example, a negative impact of $3 \%$ decrease of the power generation occurred when scenario 4 of the DSPRO replaced scenario 2 of the conventional PRO process [Table 2]. On the contrary, a tangible increase of the power generation occurred when scenario 4 of the DSPRO replaced scenario 2 of the conventional PRO for the Dead Sea-seawater and Dead Sea-RO brine salinity gradients. Power generation increased up to $14 \%$ when scenario 4 of the DSPRO replaced scenario 2 of the conventional PRO. Scenario 5 represented a DSPRO process of one PRO module in the first stage and two PRO modules in second stage of the DSPRO process. Compared with scenario 3 of the conventional PRO, about $15 \%$ increase of the power generation was achieved in the case of Dead Sea-RO brine salinity gradient resource when scenario 5 of the DSPRO was applied. For Dead Sea-wastewater salinity gradient resource, scenario 5 of the DSPRO resulted in $6 \%$ decrease of the power generation compared to scenario 3 of the conventional PRO. In scenario 6 of the DSPRO, two PRO modules were in the first stage and one PRO module was in the second stage of the DSPRO process. $18 \%$ increase of the 
power generation was achieved for Dead Sea-RO brine salinity gradient resource when scenario 6 of the DSPRO process replaced scenario 3 of the conventional PRO process. For the Dead Sea-wastewater, seawater-wastewater and RO brine-wastewater salinity gradients, scenario 6 of the DSPRO demonstrated a neutral performance compared with scenario 3 of the conventional PRO; i.e. no significant change of the power generation. Therefore, DSPRO has no advantage over the conventional PRO at low feed concentrations such as wastewater and river water.

Table 2 summarizes the comparison results for scenarios 1 to 6 . Apparently, scenarios 4 to 6 of the DSPRO process were not advantageous when a low concentration wastewater was the feed solution. For a relatively high concentration feed solutions, such as seawater and RO brine; scenarios 4 to 6 of the DSPRO process outperformed scenarios 2 and 3 of the conventional PRO process respectively. Scenario 6 of the DSPRO demonstrated up to $18 \%$ increase of the power generation compared to scenario 3 of the conventional PRO. This suggests that DSPRO process performs better for the salinity gradient resources with a relatively high feed concentration due to the severe concentrative concentration polarization developed on the feed side. Intense concentration polarization decreases the net driving force across the PRO membrane and energy yield of the process. This issue was alleviated in the DSPRO process since raw feed solution was introduced in the second stage of the DSPRO process.

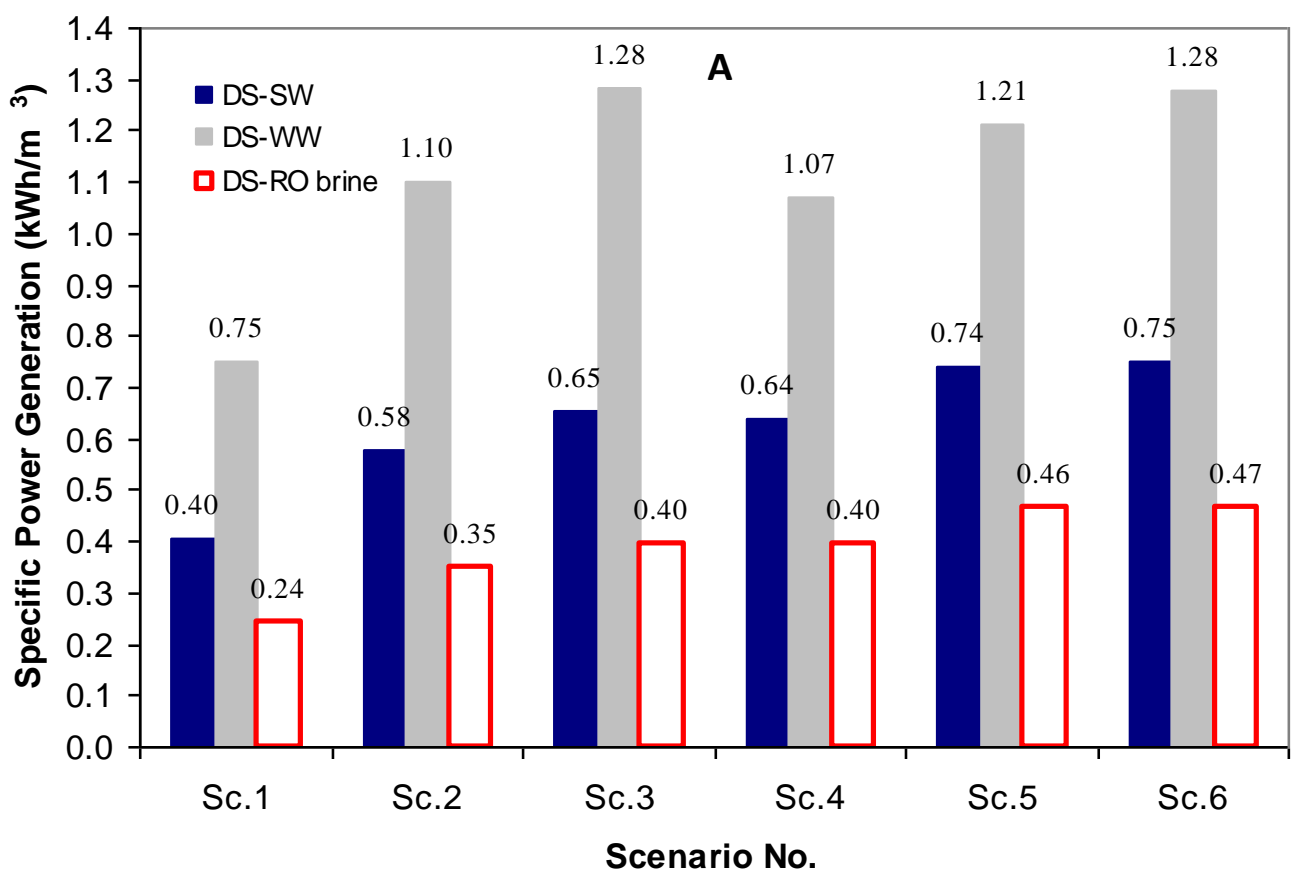




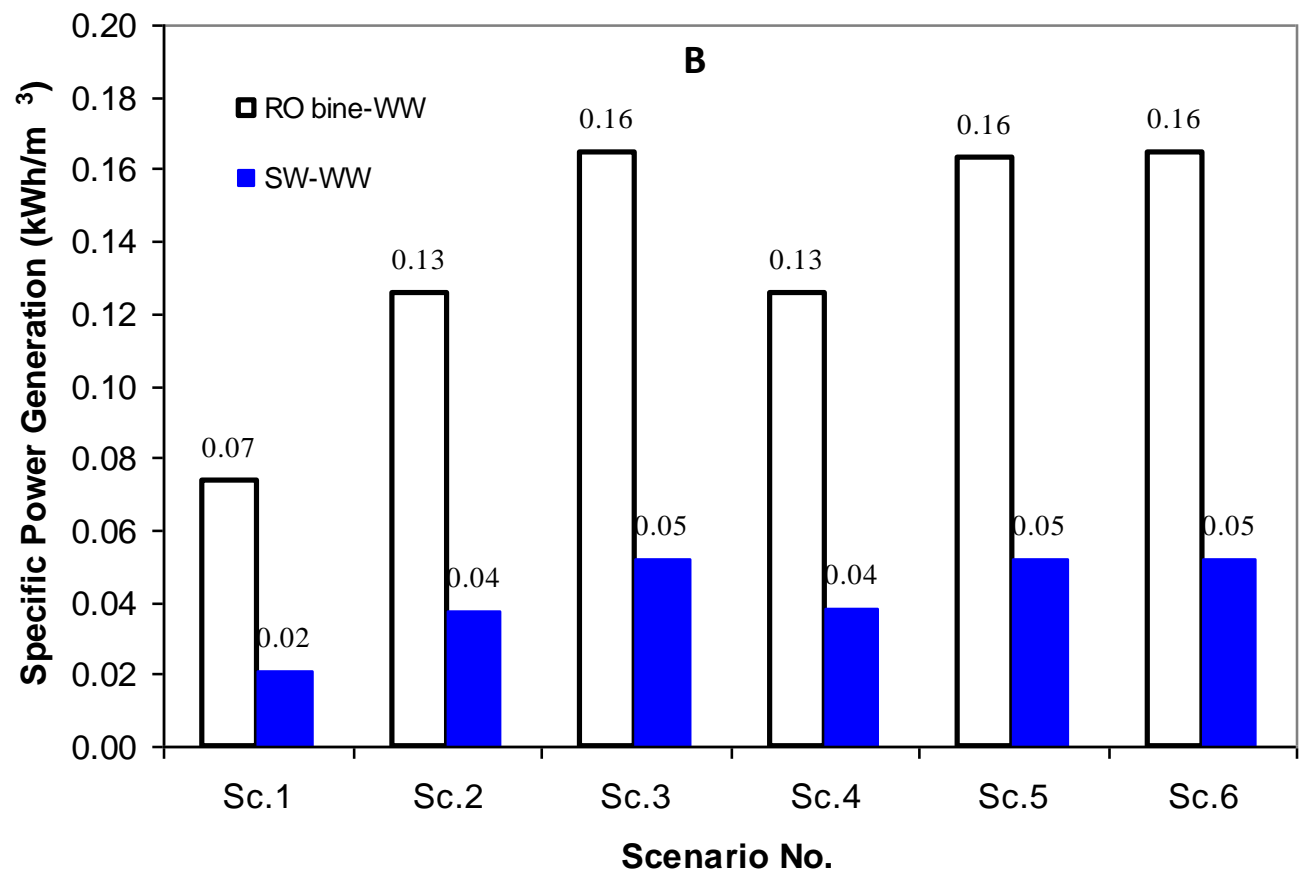

Figure 4: Maximum specific energy yield of the DSPRO: A) salinity gradient resources Dead Sea-seawater, Dead Sea-wastewater, and Dead Sea-RO brine; B) RO brinewastewater and seawater-wastewater. The normalized membrane of the second stage $A_{2 \text {-norm }}$ for scenario 5 is $27 \%, 11 \%, 45 \%, 19 \%$, and $17 \%$ for Dead Sea-seawater, seawaterwastewater, Dead Sea-wastewater, Dead Sea-RO brine, and RO brine-wastewater respectively. The normalized membrane of the second stage $A_{2 \text {-norm }}$ for scenario 6 is $40 \%$, $20 \%, 66 \%$, 27\%, and 28\% for Dead Sea-seawater, seawater-wastewater, Dead Seawastewater, Dead Sea-RO brine, and RO brine-wastewater respectively.

Table 2: Changes of maximum specific energy of salinity gradient resources at different membrane modules arrangements in conventional and dual stage PRO process.

\begin{tabular}{|c|c|c|c|c|c|}
\hline \multirow{2}{*}{$\begin{array}{c}\text { Scenarios } \\
\text { comparison }\end{array}$} & \multicolumn{5}{|c|}{ Change of power generation (\%) for salinity gradient resource } \\
\cline { 2 - 6 } & DS-SW & DS-WW & DS-RO brine & SW-WW & RO brine-WW \\
\hline 2 vs. 4 & $10 \%$ & $-3 \%$ & $14 \%$ & $0 \%$ & $0 \%$ \\
\hline 3 vs. 5 & $14 \%$ & $-6 \%$ & $15 \%$ & $-1 \%$ & $0 \%$ \\
\hline 3 vs. 6 & $15 \%$ & $-0.5 \%$ & $18 \%$ & $0 \%$ & $0 \%$ \\
\hline
\end{tabular}

To better understand the behavior of PRO process, we investigated the $S_{x j-N}$ along the PRO module for each stage of the DSPRO process. In the PRO process, water permeation across the membrane resulted in the dilution and concentration of draw and feed solution. Consequently, a gradual drop of the membrane flux occurred as a result of simultaneous reduction of the net driving force [Figure 2B]. The slightly depleted salinity gradient resource induced less water permeation flow when it travels from one module to other. Therefore, conventional PRO process suffered from a gradual deterioration of 
the net driving force across the PRO membrane. In the DSPRO process, a raw feed solution was applied in the second stage of the DSPRO process; this led to a chemical potential jump and increased the osmotic pressure difference across the membrane. In other words, the depleted salinity gradient resource was rejuvenated when it entered the second stage of the DSPRO process. $S_{x j-N}$ was plotted along the PRO membrane module for scenarios 1 to 6 as illustrated in Figure 5. For a single PRO membrane module PRO process, scenario 1 , a sharp drop of $S_{x j-N}$ occurred along the membrane module. This was mainly due to the high water permeation induced by the elevated osmotic pressure gradient across the membrane. For example, $S_{x j-N}$ at the outlet of the first PRO module of stage one ( 1 meter from the entrance) was $68 \%$ for the Dead Seawastewater salinity gradient [Figure $5 \mathrm{~B}$ ]; this suggests that $32 \%$ of the salinity gradient energy was recovered by the first PRO module. For Dead Sea-seawater and Dead Sea-RO brine, $S_{x j-N}$ at the outlet of the first PRO module of stage one was $58 \%$ and $55 \%$ of the maximum specific energy respectively [Figure $5 \mathrm{~A}$ and $5 \mathrm{C}$ ]; i.e. $42 \%$ and $45 \%$ of the Dead Sea-seawater and Dead Sea-RO brine salinity gradient energy respectively, was recovered by the first PRO module of stage one. The results suggest that for a given concentration of draw solution, energy recovery by the PRO process increased at higher feed concentrations due to the rapid decrease of chemical potential difference across the PRO membrane. For RO brine-wastewater and seawater-wastewater salinity gradients, $S_{x j-N}$ at the outlet of the first PRO module of stage one was $82 \%$ and $88 \%$ [Figure 5D, and 5E]. Apparently, the energy recovered by the first PRO module of stage one was, respectively, $12 \%$ and $18 \%$ of the maximum specific energy which indicated that lower energy was harvested from these salinity gradient resources compared with the Dead Sea-seawater and Dead Sea-RO brine. Indeed, this was due to the lower chemical potential difference across the membrane which affected the permeation flow.

Adding a second PRO module to the first stage of the PRO process, scenario 2, increased the energy recovery from the salinity gradient resource. Energy recovery by the second PRO module, however, was less than that of the first PRO module because of the lower osmotic energy of the salinity gradient to the second PRO module. For example, $S_{x j-N}$ at the end of the second PRO module of stage one (2 meter from the entrance) was $43 \%$, $58 \%$ and $39 \%$ for Dead Sea-seawater, Dead Sea-wastewater and Dead Sea-RO brine salinity gradients respectively; this suggests that $10 \%$ to $16 \%$ of the salinity gradient energy was harvested by the second module. In the case of RO brine-wastewater and seawater-wastewater, only $5 \%$ to $10 \%$ of the salinity gradient energy was recovered by the second PRO module of the PRO process. Around 6\% of the salinity gradient energy was recovered by the third PRO module of the PRO process, scenario 3. This holds for the all salinity gradient resources. The low energy recovery by the third PRO module was an indicative of the degeneration of the draw solution which resulted in a reduced osmotic pressure gradient across the membrane. Energy recovery from a salinity gradient, obviously, decreased in the order from module one to three.

A sharp increase of the osmotic energy potential occurred when the second stage PRO process was introduced, scenarios 4 to 6 [Figure 5]. The raw feed solution introduced at 
the second stage of the DSPRO process caused a sharp jump of the salinity gradient osmotic energy [Figure 5A and $5 \mathrm{C}$ ]. Relatively, a significant chemical potential difference was re-built across the PRO membrane and resulted in a substantial increase of the osmotic energy compared to that of the first stage of the PRO process. This was particularly apparent in the cases of coupling Dead Sea water draw solution with seawater or RO brine feed solution; though the change of the osmotic energy was less noticeable for the salinity gradient resources used wastewater as a feed solution. This was because of the low concentration of wastewater compared to seawater and RO brine feed solutions. Introducing a raw wastewater feed to the second stage of scenarios 5 and 6 of the DSPRO process did not significantly affect the chemical potential difference across the membrane; hence a subtle increase of the osmotic energy potential occurred [Table 3]. For Dead Sea- wastewater, seawater-wastewater and RO brine-wastewater salinity gradients, $1 \%$ to $2 \%$ increase of the $S_{x j-N}$ occurred by introducing a second stage PRO according to scenarios 5 and 6 of the DSPRO process. Meanwhile, between $12 \%$ and $23 \%$ increase of the $S_{x j-N}$ was achieved by introducing the second stage of the DSPRO process for Dead Sea-seawater and Dead Sea-RO brine salinity gradient resources. In general, the extent of $S_{x j-N}$ change was attributed to the chemical concentration difference across the PRO membrane. Table 3, however, shows that scenario 6 demonstrated higher increase of the specific energy than scenario 5 of the DSPRO process for the Dead Sea-seawater and Dead Sea-RO brine salinity gradient resources.

According to scenario 6 of the DSPRO, there was $19 \%$ and $23 \%$ increase of the $S_{x j-N}$ for the Dead Sea-seawater and Dead Sea-RO brine Salinity gradient resources respectively [Table 3]. The corresponding values for scenario 5 of the DSPRO process were $12 \%$ and $16 \%$ respectively for Dead Sea-seawater and Dead Sea-RO brine Salinity gradient resources. As such, scenario 6 performed better than scenario 5 of the DSPRO process. However, there was not a tangible advantage of scenario 6 over scenario 5 of the DSPRO for the Dead Sea-wastewater, RO brine-wastewater, and seawater-wastewater salinity gradient resources. It should be noted that for scenario 4 of the DSPRO process, adding a second stage PRO process would have the same initial impact of scenario 5 of the DSPRO. Scenarios 4 and 5, the second stage PRO process was introduced after the first PRO membrane module of stage one of the DSPRO.

Despite the unsatisfactory performance of DSPRO process in the case of wastewater feed solution. The process demonstrated $10 \%$ to $18 \%$ higher energy yield than the conventional PRO process for the Dead Sea-seawater and Dead Sea-RO brine salinity gradients [Figure 4]. DSPRO performance varied according to the arrangement of membrane modules of the first and second stage of the DSPRO process which is represented in scenarios 5 and 6 . The latter scenario demonstrated slightly higher energy yield than scenario 5 [Table 2]. This was attributed to the higher osmotic energy of the salinity gradient resource in the case of scenario 6 of the DSPRO. This explains the slightly higher energy yield of scenario 6 compared to scenario 5 [Figure 4A]. It should be noted, however, that energy recovery from a salinity gradient resource by the PRO 
process decreases gradually with increasing the number of modules in the stage due to the depletion of the chemical potential difference across the membrane.
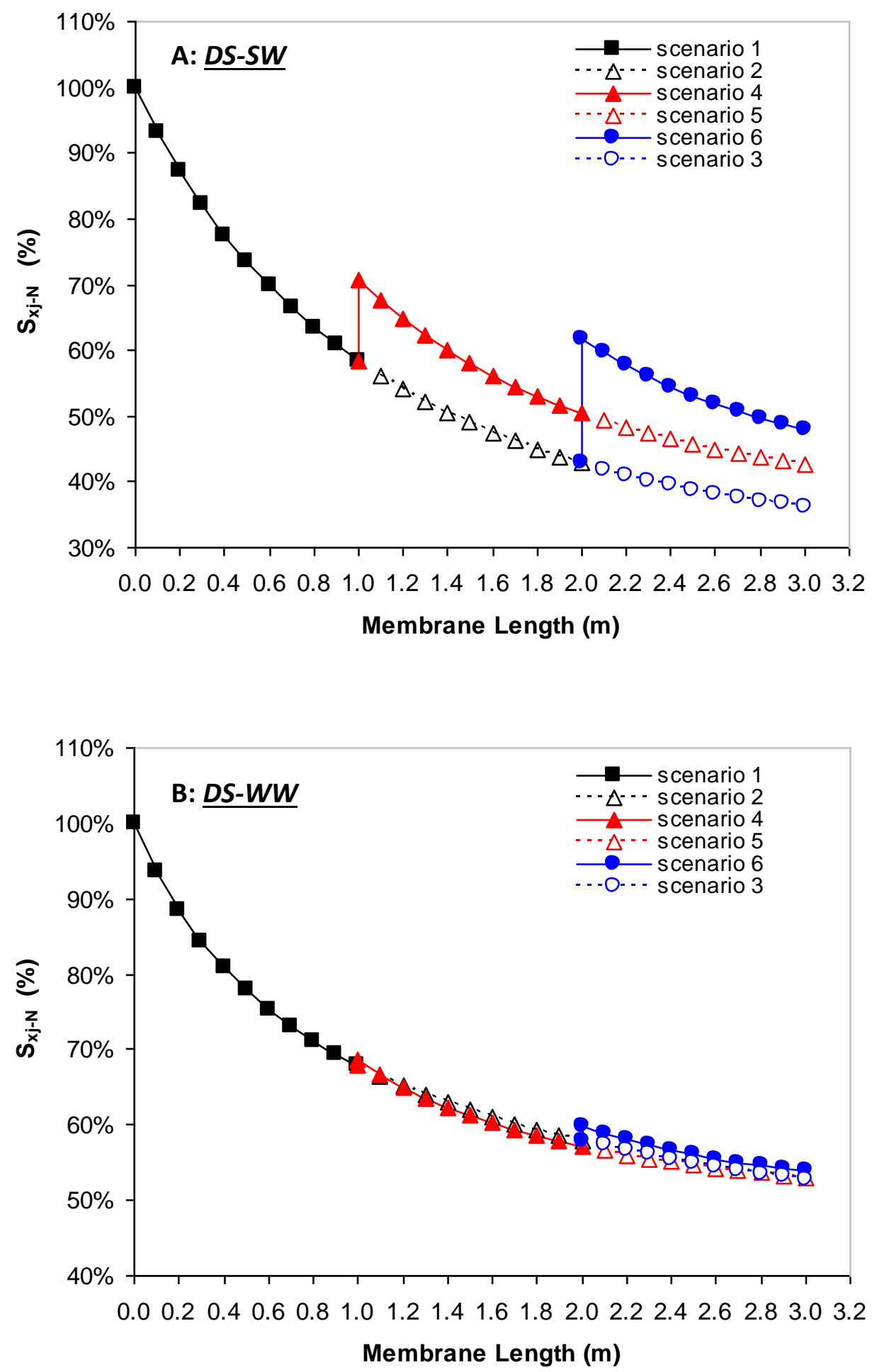

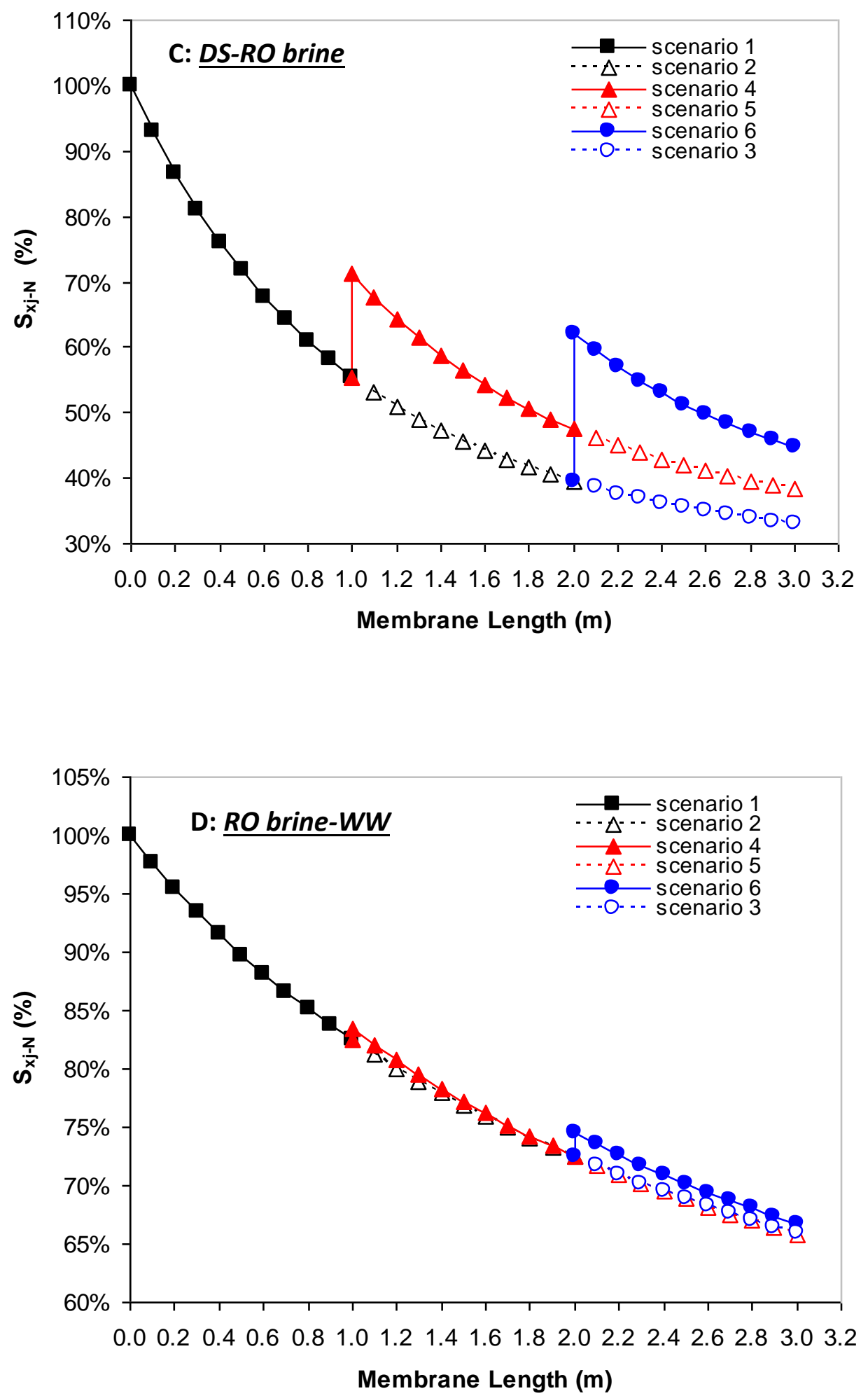


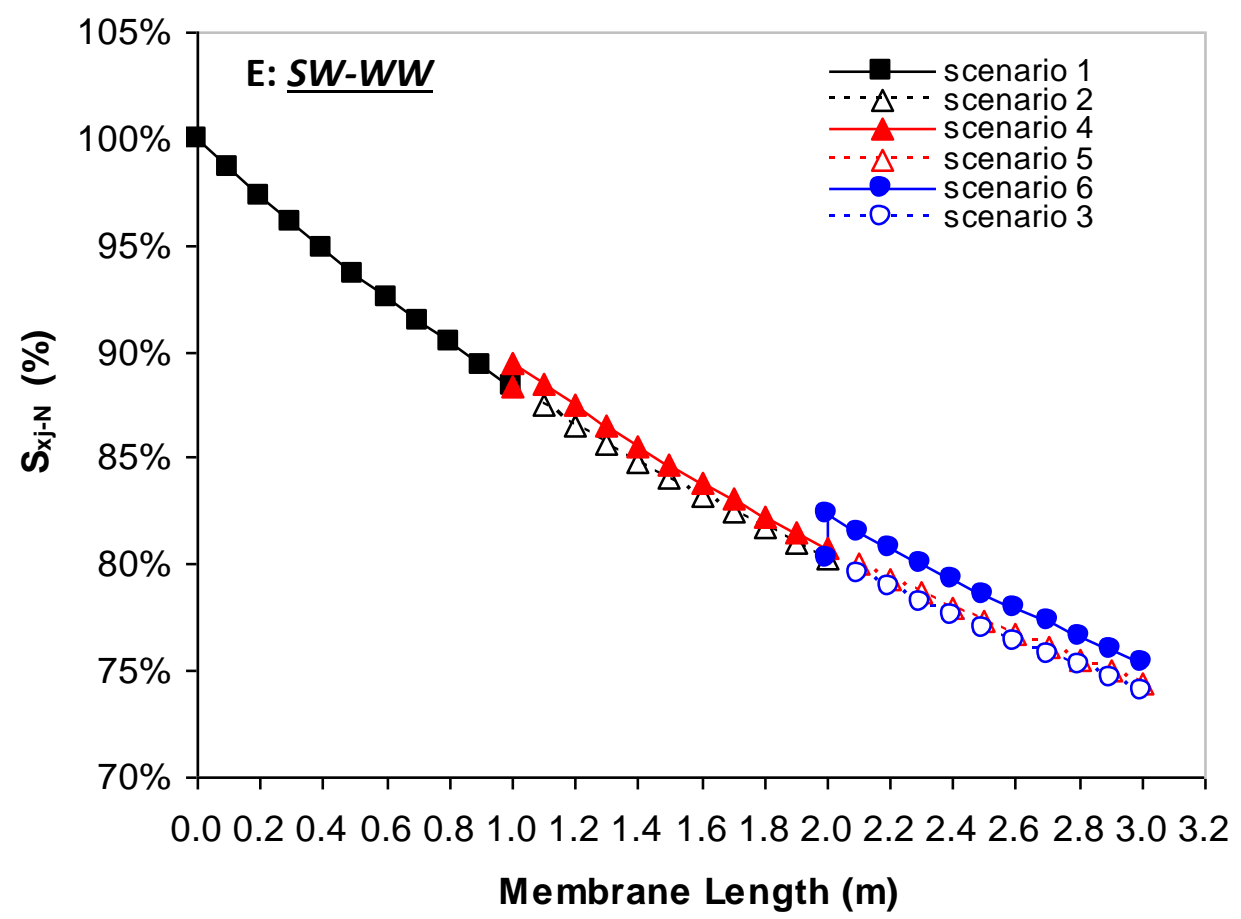

Figure 5: Specific energy in conventional (single stage) PRO and DSPRO modules in the pressure vessel: A) Dead Sea-seawater; B) Dead Sea-wastewater; C) Dead Sea-RO brine;

D) RO brine-wastewater; E) seawater-wastewater. The normalized membrane of the second stage $A_{2 \text {-norm }}$ for scenario 5 was $27 \%, 11 \%, 45 \%, 19 \%$, and $17 \%$, and for scenario 6 $40 \%, 20 \%, 66 \%, 27 \%$, and $28 \%$, respectively.

Table 3: \% increase of $S_{x-N}$ of the salinity gradient resource by introducing the second PRO stage; dual stage PRO process was introduced either after the first PRO module of first stage or after the second PRO module of the first stage.

\begin{tabular}{|c|c|c|c|c|c|}
\hline \multirow{2}{*}{ Scenario } & \multicolumn{5}{|c|}{ Salinity gradient resources $S_{x-N}$ increase } \\
\cline { 2 - 6 } & DS-SW & DS-WW & DS-RO brine & RO brine-WW & SW-WW \\
\hline $4 \& 5$ & $12 \%$ & $1 \%$ & $16 \%$ & $1 \%$ & $1 \%$ \\
\hline 6 & $19 \%$ & $2 \%$ & $23 \%$ & $2 \%$ & $2 \%$ \\
\hline
\end{tabular}

\section{Limitations and impact of feed pressure:}

One of the key operating parameters in the PRO process is the applied hydraulic pressure across the membrane. Hydraulic pressure affects power density of the PRO process; previous studies concluded that the maximum amount of power density occurs at hydraulic pressure equals to half of the osmotic pressure gradient across the membrane: i.e. $\Delta P=\Delta \pi / 2$ [29]. Theoretically, it is possible to increase the hydraulic 
pressure of draw solution to $\Delta \pi / 2$ for an optimum PRO performance. But technically, this is not always feasible especially when the chemical potential difference between the draw and feed solution is significant. Technical obstacles, such as the mechanical strength of the PRO membrane, impede the application of elevated hydraulic pressures to prevent membrane damage. This is particularly important in the case of a significant osmotic pressure difference between the draw and feed solutions. For example, the optimum hydraulic pressure, $\Delta P$, to achieve a maximum power density for the Dead Seaseawater and the Dead Sea-RO brine salinity gradient resources are 106 bar and 91 bar respectively. Although these hydraulic pressures can theoretically be delivered, the status of current PRO membranes does not allow increasing the hydraulic pressure to such levels as it will damage the membrane. DSPRO plant using Dead Sea draw solution can be coupled with a Reverse Osmosis desalination plant for power generation and fresh water supply which is much needed in that region. Both Mediterranean seawater and Red Sea can be used as the feed water of the DSPRO process. Dead Sea coupling with RO brine, for example, would not only generate power from a renewable resource but also reduce the environmental impact of desalination process as the diluted draw solution returns to Dead Sea to replenish water evaporation [8]. The other advantage of Dead Sea-RO brine osmotic power plant is that the RO brine feed solution would not require pretreatment since it has already been treated for the $\mathrm{RO}$.

Figure 6 shows the impact of various hydraulic feed pressures on the power generation of the first stage and the second stage of the DSPRO process. Total specific power generation, $E s-t$, was calculated as the sum of specific power generation of the first and the second stage of the DSPRO process. For Dead Sea-seawater, the specific power generation of the first stage of the DSPRO process reached a maximum amount of a $0.425 \mathrm{kWh} / \mathrm{m}^{3}$ at a 110 bar hydraulic feed pressure; i.e. $\Delta P=\Delta \pi / 2$ [Figure 6A]. For the second stage of the DSPRO process, the specific power generation reached a maximum amount of a $0.242 \mathrm{kWh} / \mathrm{m}^{3}$ at a 90 bar; this hydraulic pressure was less than $\Delta \pi / 2$. In the case of Dead Sea-RO brine [Figure 6B], the specific power generation of the first stage of the DSPRO process reached a maximum amount of a $0.255 \mathrm{kWh} / \mathrm{m}^{3}$ at $90 \mathrm{bar}$; this hydraulic pressure is equal to $\Delta \pi / 2$. However, the specific power generation of the second stage of the DSPRO process reached a maximum value of a $0.16 \mathrm{kWh} / \mathrm{m}^{3}$ at 85 bar instead of 90 bar. For the Dead Sea-seawater salinity gradient resource, the total specific power generation of the DSPRO process reached a maximum amount of a 0.61 $\mathrm{kWh} / \mathrm{m}^{3}$ at 100 bar hydraulic pressure. Whilst for the Dead Sea-RO brine salinity gradient resource, the total specific power generation reached a maximum value of 0.41 $\mathrm{kWh} / \mathrm{m}^{3}$ at 85 bar hydraulic pressure instead of a 90 bar for the conventional PRO process. Interestingly, the specific power generation of DSPRO process reached a maximum amount at a hydraulic pressure less than $\Delta \pi / 2$. This suggests that DSPRO process can be operated at hydraulic pressures less than that recommended for the conventional single stage PRO process. As such, the operating cost of the DSPRO would be slightly decreased due to the application of lower hydraulic pressure than required for the conventional PRO process. Furthermore, introducing a second stage PRO process 
contributed $37 \%$ and $39 \%$ to the total power generation by the DSPRO process for the Dead Sea-seawater and Dead Sea-RO brine salinity gradient respectively.

Applying elevated feed pressures, is not feasible and may compromise the mechanical strength of the PRO membrane in the long term. Energy recovery from a salinity gradient resource would be higher for the DSPRO than the conventional PRO process. For example, at a moderate applied hydraulic pressure of 50 bar, power generation of the Dead Sea-seawater salinity gradient resource was $0.29 \mathrm{kWh} / \mathrm{m}^{3}$ for the conventional PRO process but increased to $0.488 \mathrm{kWh} / \mathrm{m}^{3}$ for the DSPRO process. As such, DSPRO process achieved $67 \%$ increase of the power generation compared to the conventional PRO process. For the Dead Sea-RO brine salinity gradient resource, power generation at 50 bar hydraulic pressure was $0.195 \mathrm{kWh} / \mathrm{m}^{3}$ and $0.328 \mathrm{kWh} / \mathrm{m}^{3}$ for the conventional PRO and DSPRO process respectively. This suggests that DSPRO achieved $68 \%$ more power generation than the conventional PRO process. This higher power density achieved by the DSPRO would increase the energy output of the osmotic power plant without compromising the cost significantly. As abovementioned, adding a second stage PRO process would not require a high pressure pump, feeds pretreatment, and the PRO membrane area is proportional to the feed flow rate in second stage. Luckily, the cost of new Toyobo PRO membranes is equal to that of the RO membranes.

Dead Sea coupling with seawater or RO brine forms one of the most studied salinity gradient resources $[8,17,25]$. Characteristically, this salinity gradient will be well invested by the DSPRO process for power generation. Dead Sea salinity gradient requires hydraulic pressure over 90 bar when it is coupled with seawater or RO brine. Commercial PRO Hollow Fiber (HF) membranes have been reported to operate at 30 bar hydraulic pressure using RO brine-wastewater salinity gradient [10]. For Dead Seaseawater using scenario 6 of the DSPRO process and 30 bar hydraulic pressure resulted in a power generation of a $0.42 \mathrm{kWh} / \mathrm{m}^{3}$; this is about $35 \%$ of the maximum specific energy of the salinity gradient resource. The corresponding power generation for a DSPRO process operating at 106 bar hydraulic pressure was $0.75 \mathrm{kWh} / \mathrm{m}^{3}$ which $64 \%$ of the maximum specific energy of the salinity gradient resource. The other advantage of the DSPRO process is the low membrane fouling which increases at high recovery rates or when a low quality feed solution such as wastewater effluent is applied. Chemicals use due to membrane cleaning or fouling control would be reduced accordingly.

PRO process, in general, performs better at elevated chemical potential difference across the membrane because of the high osmotic energy of the salinity gradient resource. Unfortunately, the sever concentration polarization effects compromises the performance of PRO process; this is particularly important when high concentration draw solution such as Dead Sea is coupled with seawater or RO brine. In such case, introducing a second stage PRO process would increase the chemical potential difference across the membrane and the specific energy of the salinity gradient resource increases as well. The novel design of DSPRO in which a raw feed solution is introduced to the second stage of the DSPRO process will reduce the effect of concentrative 
concentration polarization. Though, the advantage of DSPRO is less obvious in the case of low salinity feed solution, such as wastewater, due to the negligible concentrative concentration polarization.
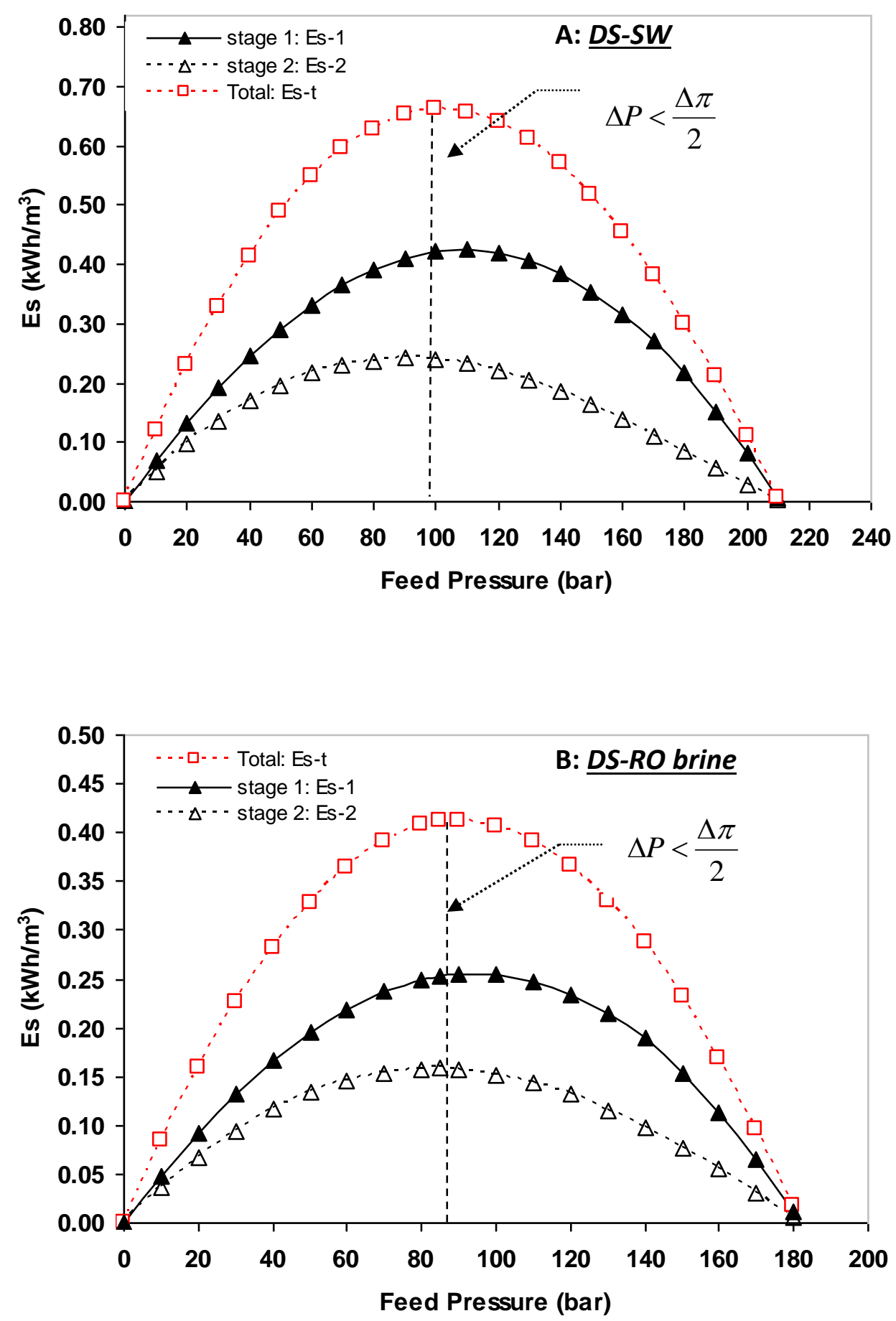

Figure 6: Impact of feed pressure on the specific power generation and the maximum available specific energy of salinity gradient resource: A) Dead Sea-Seawater salinity 
gradient resource; B) Dead Sea-RO brine salinity gradient resource. Dead Sea is $5 \mathrm{M} \mathrm{NaCl}$, seawater is $0.6 \mathrm{M} \mathrm{NaCl}$, and $\mathrm{RO}$ brine is $1.2 \mathrm{M} \mathrm{NaCl}$.

\section{Conclusion:}

Single and dual stage PRO process was evaluated for power generation using different types of salinity gradient resources and membrane module configurations in the pressure vessel. Ignoring the membrane fouling, DSPRO outperformed the conventional PRO process especially at high feed concentration. The second stage PRO process rejuvenated the osmotic energy of salinity gradient resources by introducing less concentrated draw solution and decreased the effect of concentration polarization. This increased the harvested osmotic energy by the DSPRO process. For low salinity feed solution such as river water and wastewater effluent, staging the PRO process can not be easily justified when membrane fouling is ignored due to its average performance compared to the conventional process. The simulation results found that the maximum power density of DSPRO was achieved at a hydraulic pressure less than $\Delta \pi / 2$. The increase of membrane area was found to increase the energy harvested by the PRO process but had limited effect on the process performance due to the intensive concentration polarization effects. Practically, DSPRO process benefits from the high osmotic potential of salinity gradient due to its configuration. Applying fresh feed solution in the second stage of the DSPRO process remains one of the key parameters in the process design which significantly improved the process energy output.

\section{Acknowledgement}

The authors wish to acknowledge the European Commission (DG for Research \& Innovation) for its financial support in the EU 7th Framework Program SFERA-II project (Grant Agreement no. 312643).

\section{References:}

[1] Wei He, Jihong Wang, Feasibility study of energy storage by concentrating/desalinating water: Concentrated Water Energy Storage, Applied Energy, V 185 (2017), 872-884

[2] Jonathan Maisonneuve, Claude B. Laflamme, Pragasen Pillay, Experimental investigation of pressure retarded osmosis for renewable energy conversion: Towards increased net power, Applied Energy, V 164 (2016), 425-435

[3] Eanna Farrell, Mohamed I. Hassan, Ramato A. Tufa, Arttu Tuomiranta, Ahmet H. Avci, Antonio Politano, Efrem Curcio, Hassan A. Arafat, Reverse electrodialysis powered greenhouse concept for water- and energy-self-sufficient agriculture, Applied Energy, $\mathrm{V}$ 187 (2017), 390-409 
[4] S. Loeb, F. Van Hessen, D. Shahaf, Production of energy from concentrated brines by pressure-retarded osmosis: II. Experimental results and projected energy costs, Journal of Membrane Science, V 1 (1976), 249-269.

[5] K.L. Lee, R.W. Baker, H.K. Lonsdale, Membranes for power generation by pressureretarded osmosis, Journal of Membrane Science, V 8 (1981), 141-171.

[6] T. Thorsen, T. Holt, The potential for power production from salinity gradients by pressure retarded osmosis, Journal of Membrane Science, V 335 (2009), 103-110.

[7] G. Han, Sui Zhang, X. Li, T. S. Chung, Progress in pressure retarded osmosis (PRO) membranes for osmotic power generation, Progress in Polymer Science, V 51 (2015), 127.

[8] S. Loeb, Energy production at the Dead Sea by pressure-retarded osmosis: challenge or chimera?, Desalination, V 120 (1998), 247-262.

[9] S. Loeb, L. Titelman, E. Korngold, J. Freiman, Effect of porous support fabric on osmosis through a Loeb-Sourirajan type asymmetric membrane, Journal of Membrane Science, V 129 (1997), 243-249.

[10] K. Saito, M. Irie, S. Zaitsu, H. Sakai, H. Hayashi, A. Tanioka, Power generation with salinity gradient by pressure retarded osmosis using concentrated brine from SWRO system and treated sewage as pure water, Desalination and Water Treatment, V 41 (2012), 114-121.

[11] G. Han, S. Zhang, X. Li, T. S. Chung, High performance thin film composite pressure retarded osmosis (PRO) membranes for renewable salinity-gradient energy generation, Journal of Membrane Science, V 440 (2013), 108-121.

[12] S. Chou, R. Wang, L. Shi, Q. She, C. Tang, A. G. Fane, Thin-film composite hollow fiber membranes for pressure retarded osmosis (PRO) process with high power density, Journal of Membrane Science, V 389 (2012), 25-33.

[13] N. Y. Yip, A. Tiraferri, W. A. Phillip, J. D. Schuiffman, L. A. Hoover, Y. C. Kim, M. Elimelech, Thin-Film Composite Pressure Retarded Osmosis Membranes for Sustainable Power Generation from Salinity Gradients, Environmental Science and Technology; V 45 (2011), 4360-4369.

[14] Y. C. Kim, M. Elimelech, Potential of osmotic power generation by pressure retarded osmosis using seawater as feed solution: Analysis and experiments, Journal of Membrane Science, V 429 (2013), 330-337.

[15] A. Altaee, G. Zaragoza, A. Sharif, Pressure retarded osmosis for power generation and seawater desalination: Performance analysis, Desalination, V 344 (2014), 108-115 [16] J. L. Prante, J. A. Ruskowitz, A. E. Childress, A. Achilli, RO-PRO desalination: An integrated low-energy approach to seawater desalination, Applied Energy, V 120 (2014), 104-114.

[17] S. Lin, A. P. Straub, M. Elimelech, Thermodynamic limits of extractable energy by pressure retarded osmosis, Energy Environmental Science, V 7 (2014), 2706-2714

[18] A. Altaee, G. J. Millar, G. Zaragoza, Integration and Optimization of Pressure Retarded Osmosis with Reverse Osmosis for Power Generation and High Efficiency Desalination, Energy, V 103 (2016), 110-118. 
[19] A. Altaee, P. Palenzuela, G. Zaragoza, A.A. Al Anezi, Single and Dual Stage ClosedLoop Pressure Retarded Osmosis for Power Generation: Feasibility and Performance, Applied Energy, V 191 (2017), 328-345.

[20] A. Altaee, A. Sharif, Pressure Retarded Osmosis: Advancement in the Process Applications for Power Generation and Desalination, Desalination, V 356 (2015), 31-46.

[21] M. Kurihara, M. Hanakawa, Mega-ton Water System: Japanese national research and development project on seawater desalination and wastewater reclamation, Desalination, V (308) 2013, 131-137

[22] S. Loeb, One hundred and thirty benign and renewable megawatts from Great Salt Lake? The possibilities of hydroelectric power by pressure-retarded osmosis, Desalination, V 141 (2001), 85-91

[23] K. Touati, F. Tadeo, Study of the Reverse Salt Diffusion in pressure retarded osmosis: Influence on concentration polarization and effect of the operating conditions, Desalination, $V 389$ (2016), 171-186

[24] Y. Xu, X. Peng, C. Y. Tang, Q. S. Fu, S. Nie, Effect of draw solution concentration and operating conditions on forward osmosis and pressure retarded osmosis performance in a spiral wound module, Journal of Membrane Science, V 348 (2010), 298-309.

[25] Ali Altaee, Adel Sharif, Guillermo Zaragoza, Dual stage PRO process for power generation from different feed resources, European Desalination Conference, 10-14 May 2015 Palermo, Italy

[26] A. Altaee, N. Hilal, Dual Stage PRO Power Generation from Brackish Water Brine and Wastewater Effluent Feeds, Desalination, Volume 389 (2016), 68-77.

[27] W. He, Y. Wang, M. H. Shaheed, Enhanced energy generation and membrane performance by two-stage pressure retarded osmosis (PRO), Desalination, V 359 (2015), 186-199

[28] G. Han, Q. Ge, T-S. Chung, Conceptual demonstration of novel closed-loop pressure retarded osmosis process for sustainable osmotic energy generation, Applied Energy, $\mathrm{V}$ 132 (2014), 383-393

[29] A. Achilli, T. Y. Cath and A. E. Childress, Power generation with pressure retarded osmosis: An experimental and theoretical investigation, Journal of Membrane Science, V 343 (2009), 42-52. 